\title{
CASOS HETEROGÉNEOS PARA LA COMPRENSIÓN DE LA VIOLENCIA EN VENEZUELA
}

\author{
Ángel Acuña Delgado ${ }^{1}$ \\ Universidad de Granada
}

Resumen: En el presente ensayo utilizamos algunos de los datos ofrecidos por el Observatorio Venezolano de Violencia, investigaciones puntuales y noticias de prensa, para establecer un amplio marco de referencia sobre el contexto espacial, temporal y circunstancial que afecta a la violencia en Venezuela. No obstante, el objetivo principal invita a reflexionar en torno a cuatro casos concretos de situaciones violentas vividas en primera persona, que por su diversidad ayudan a entender el amplio espectro en donde se desarrolla, las personas que son afectadas, sus reacciones, los motivos desencadenantes y las consecuencias que produce.

Tras la introducción, hacemos una aproximación teórica a la violencia para aclarar mínimamente el concepto en su compleja heterogeneidad. Describimos a grandes trazos el contexto histórico en relación con la violencia que vive el país, como marco de referencia situacional. Ofrecemos seguidamente cuatro casos heterogéneos de comportamientos violentos basados en la propia experiencia que permiten hacer pensar. Y apoyados en dichos casos reflexionamos por último para tratar de comprender cuales son las claves del fenómeno desde una perspectiva contextual y multicausal.

Palabras Clave: Venezuela, violencia, conflicto, política, anomia.

АвSTRACT: In the present essay we use some of the data provided by the Venezuelan Violence Observatory, punctual investigations and news reports to establish a broad framework about the spatial, temporal and circumstantial context that affects violence in Venezuela. However the main objective invites to ponder on four specific instances of violent situations experienced in first person, which in turn help to understand the wide spectrum where it un folds, the people who are affected, their reactions, the triggers reasons and the consequences it produces.

\footnotetext{
1 acuna@ugr.es
} 
Following the introduction, we do a theoretical approach to violence to clarify minimally the concept in its complex heterogeneity. We describe the broad outlines of the historical context in relation to violence in the country, as situational framework. Then offer four heterogeneous cases of violent behavior based on the experience that they allows thinking. And supported in such cases, we finally ponder to try to understand which are the keys of the phenomenon from a contextual and multicausal perspectives.

KEYwords: Venezuela, violence, conflict, politics, anomia.

\section{Introducción}

Uno de los rasgos más característicos de la actual República Bolivariana de Venezuela es el progresivo aumento de la inseguridad ciudadana y su normalización en la vida cotidiana. Tema dominante que ocupa las conversaciones cotidianas de los venezolanos y las noticias en los medios de comunicación nacional. Los motivos que conducen a tal situación pueden ser muchos y variados: descontento y desigualdad social, corrupción y polarización política, abusos de autoridad policial y militar, sensación de impunidad en la ejecución de delitos y falta de justicia, fraudes financieros, etc. Sea como sea, lo cierto es que la espiral de violencia en Venezuela ha ido creciendo cada vez más alimentada por su propia inercia, hasta alcanzar unas proporciones difícilmente soportables.

Unido a ello, el panorama se torna más desolador aún al apreciar cómo las fuerzas del orden, las instituciones estatales encargadas de asegurar la paz social, lejos de controlar las situaciones conflictivas y violentas, contribuyen a su fomento.

Por la envergadura y consecuencias del fenómeno, la violencia constituye en la actualidad un tema de gran interés social para la población venezolana que la sufre, y el territorio venezolano se convierte a la vez en un espacio privilegiado para su estudio científico, por el conocimiento que se puede obtener de lo que en él ocurre. Conocimiento que puede ser útil para una mejor comprensión de esa faceta del comportamiento humano, y para generar planes de actuación que mitiguen su pernicioso efecto.

Como prueba de la gran relevancia que ha cobrado en los últimos tiempos, podemos comprobar la existencia de grupos de investigación tales, como 
el denominado: «Expresiones y Representaciones de la Violencia en América Latina y el Caribe» (VALEC), creado por el Centro de Investigaciones Penales y Criminológicas (CENIPEC) de la Universidad de Los Andes, que abarca un ámbito mayor que el estrictamente venezolano; y muy especialmente, por estar centrado en el país, el «Observatorio Venezolano de Violencia» (OVV), creado en 2005, fruto de la inquietud y experiencia de varias universidades (UCV, UDO, LUZ, UCAT, UCAB, UCLA) en torno a la situación de inseguridad del país, que cuenta con la financiación de organizaciones gubernamentales y no gubernamentales para su estudio. El registro de información «se basa en cuatro derechos fundamentales: el derecho a la vida, a la integridad personal, al acceso a la justicia, y a la libertad» (http://www.observatoriodeviolencia.org.ve/site/). Dicho OVV se ha convertido en el punto de referencia para la consulta sobre la situación de violencia y percepción de inseguridad de la población venezolana.

De los datos recolectados y producidos en el último informe sobre violencia, editado con el nombre «Violencia e institucionalidad» se desprende que 2011 fue el «año más violento de la historia nacional». En 2001 se arroja la cifra de 7.960 homicidios, en 2010: 13.080 asesinatos, y en 2011: 19.336. Entre 2001 y 2011 se calcula que fueron asesinadas unas 141.487 personas en el país. El censo venezolano en 2011 es de 27.150.095 (INE, 2012), y la tasa de homicidios es de 67 por cada 100.000 habitantes, lo cual se traduce como una "grave epidemia», teniendo en cuenta que las Naciones Unidas considera "epidemia de homicidios» una tasa que sobrepase 10 homicidios por cada 100.000 habitantes (http://www.observatoriodeviolencia.org.ve/site/).

Así las cosas, en el presente ensayo utilizamos algunos de los datos ofrecidos por el OVV, investigaciones puntuales y noticias de prensa para establecer un amplio marco de referencia sobre el contexto espacial, temporal y circunstancial que afecta a la violencia en Venezuela. No obstante, el objetivo principal invita a reflexionar en torno a cuatro casos concretos de situaciones violentas vividas en primera persona, que por su diversidad ayudan a entender el amplio espectro en donde se desarrolla, las personas que son afectadas, sus reacciones, los motivos desencadenantes y las consecuencias que produce.

Tras esta breve introducción, hacemos una aproximación teórica a la violencia para aclarar mínimamente el concepto en su compleja heterogeneidad. Luego describimos a grandes trazos el contexto histórico en relación con la violencia que vive el país, como marco de referencia situacional. Ofrecemos seguidamente cuatro casos heterogéneos de comportamientos violentos basados en la propia 
experiencia que permiten hacer pensar. Y apoyados en dichos casos reflexionamos por último para tratar de comprender cuales son las claves del fenómeno desde una perspectiva contextual y multicausal.

\section{Aproximación teórica a la violencia}

Frente a la perspectiva armónica u orgánica de la sociedad, como nos recuerda García Ferrando (1990: 229) se ha desarrollado también una visión conflictiva que ayuda entender la dinámica social.

El estudio de la violencia constituye un tema clásico en las ciencias sociales del que mucho se ha dicho, tanto desde la reflexión teórica como desde la investigación empírica. Término polisémico y ambiguo que puede ir referido a acciones individuales o colectivas, organizadas o espontáneas, ritualizadas o no ritualizadas, legales o ilegales, intencionadas o no intencionadas (Martin, 2000. Cit. Garriga y Noel, 2010: 98). Término además cargado de connotaciones morales, ya que, aunque por lo común esté ligado a una acción dañina o destructora, también puede pensarse como constructor de vínculos sociales; violencia purificadora incluso, cuando se practica dentro de procesos rituales con la presencia de víctimas propiciatorias (Girard, 1983). Por otro lado, una conducta aceptada como normal en un tiempo puede ser rechazada como violenta en otro tiempo y viceversa. Fenómeno por tanto de «múltiples caras y anclajes en las distintas realidades históricas y sociales» (Feixa y Ferrándiz, 2002: 1) que es preciso considerar en su proceso y su contexto para una mejor comprensión.

Siguiendo a Guzmán (1990), si hacemos una breve aproximación teórica al concepto, encontramos cómo Marx conectaba el análisis de la violencia con las relaciones de clase y los periodos de cambio y crisis social, entendiéndola como un recurso contingente para la dominación, cuyo uso queda justificado o legitimado desde la perspectiva de las clases dominadas. (Ibid. 1990: 9).

Weber articula el concepto con los de poder, dominación, orden, legitimidad. Más allá de las clases sociales, centra la atención en los procesos de legitimación, para entender que se trata de una forma tanto de buscar imposición por la fuerza como de manifestar rebeldía. (Ibid. 1990: 13).

Durkheim considera por su parte que las fuentes del conflicto y la violencia hay que buscarlas bien en las consecuencias de la no institucionalización del 
cambio social; o bien en la coacción ejercida para el cumplimiento de normas no interiorizadas. La ausencia de normativa para dirimir conflictos que regulen la vida social, y la falta de aceptación de la normativa establecida, serían por tanto los dos niveles de análisis para una teoría de la violencia. (Ibíd. 1990: 16).

Coser vincula la violencia con la privación y la desigualdad social. El descontento originado por una situación de privación relativa, se politiza y traduce en acciones violentas contra objetos materiales y el propio sistema político. (Ibíd. 1990: 16).

Tilly enfatiza el significado y orientación política de la violencia y la conecta con la solidaridad, en cuanto a la representación de los intereses de clase en la época contemporánea, dentro de la formación y consolidación del Estado. (Ibíd. 1990: 29).

En cuanto a las tipologías elaboradas para entender el fenómeno en toda su dimensión, es preciso considerar que la violencia no solo se asocia con el uso agresivo de la fuerza física con el fin de causar algún daño, ya que los medios empleados son variados: verbales, simbólicos, morales. (Velho, 1996. Cit. Ferrándiz y Feixa, 2004: 161).

Según Tilly (Cit. Baselga y Urquijo, 1974: 99-104), los tipos históricos de los movimientos violentos producidos en los dos últimos siglos se pueden fijar en tres coordenadas básicas: la orientación de los amotinados, el volumen de la población implicada, y la forma de confrontación política. De esa manera logra distinguir lo que denomina: «violencia primitiva», ocasionada cuando dominan las luchas entre familias, gremios rivales, grupos religiosos hostiles, etc., primando motivos afectivos y de sangre; «violencia reaccionaria», orientada hacia la resolución de problemas locales ante el temor de la pérdida de derechos o privilegios adquiridos; $y$ «violencia moderna», derivada de formas de protesta organizadas a nivel macrosocial, con un marcado carácter ideológico.

Alderman (Cit. Blanchard y Cheska, 1986: 177) por su parte, distingue dos formas básicas de violencia: «violencia reactiva u hostil», que conlleva algún tipo de castigo físico o psicológico empleado fundamentalmente más como fin en sí mismo que como medio para conseguirlo; y «violencia instrumental», que entraña algún tipo de intencionalidad por causar daño o lesiones como medio para alcanzar determinados objetivos. 
Bourgois (2001. Cit. Ferrándiz y Feixa, 2004: 162-163) establece asimismo cuatro modalidades de violencia, no excluyentes entre sí, cuyos conceptos fueron acuñados por distintos autores: «violencia política» (Clastres, 1980), ejercida en nombre de una ideología, movimiento o estado político; «violencia estructural» (Galtung, 1981), establecida o impuesta por el sistema sociopolítico; «violencia simbólica» (Bourdieu, 2000), sustantivada en humillaciones por medio de sexo, raza, clase social, etc.; y «violencia cotidiana» (Scheper-Hughes, 1997), practicada entre individuos a diario por múltiples motivos. También podemos oír hablar de «violencia cultural» (Galtung, 1990), «violencia de género» (Fisas, 1998), violencia familiar, y una larga lista de términos que definen el ámbito en donde se produce.

Por otro lado, es preciso observar los distintos factores condicionantes de la violencia en determinadas situaciones, que han sido señalados desde diferentes perspectivas teóricas. Lorenz (1974) puso énfasis en el «instinto», y consideró el comportamiento agresivo en los seres humanos, como en el resto de los animales, como un atributo natural básico para la supervivencia de las especies.

Bandura (Cit. Blanchard y Cheska, 1986: 179) por su parte, apunta el «aprendizaje social» como el principal vehículo. La violencia engendra violencia y quienes se exponen permanentemente a ese tipo de comportamiento la adquiere y ejerce en el futuro.

Para Dollard et al. (Cit. Cagigal, 1976: 35) es la «frustración» el mecanismo que la desencadena. La violencia surgiría cuando no se alcanza la meta fijada al haberse bloqueado el acceso a la misma por alguna razón. Sobre todo aparece cuando el nivel de aspiración es muy superior al nivel de posibilidades reales para hacer o tener lo que se quiere.

Blanchard y Chesca (1986: 179-180) señalan la «masificación», al considerar que en la masa se pierde la individualidad y se desarrolla una especie de conciencia colectiva que los funde a todos. El inconformismo, el malestar o la indignación, sobre todo expresados colectivamente, pueden conducir a conductas violentas. También el aumento de feromonas (sustancias químicas liberadas por el organismo) en situaciones de hacinamiento se apunta como posible inductor de comportamientos agresivos y violentos.

Clarke y Marsh (Cit. García Ferrando, 1990: 227-228) entienden que el «estilo subcultural» puede ser causante del gamberrismo y de determinados 
comportamientos violentos, expresados a modo de demostración como seña de identidad por ciertos grupos sociales en su intento por diferenciarse.

Para Tylor (Cit. García Ferrando, 1990: 227) las «relaciones de clase» con respecto al Estado, y las exageradas desigualdades que se dan en su interior, constituye un factor esencial para entender el fenómeno.

Además de todo ello, también cabría considerar para entender la razón de ser de ciertas situaciones violentas: el eventual o sistemático estado de embriaguez, la inestabilidad emocional o el estado de ánimo, motivado por un estilo de vida sujeto a demasiada presión.

\section{Contexto histórico venezolano en torno a la violencia}

El conocido como "Caracazo», revuelta popular producida el 27 de febrero de 1989, bajo la presidencia de Carlos Andrés Pérez, que motivó un número indeterminado de víctimas mortales (menos de 300 según cifras oficiales), constituye para algunos un punto de inflexión que marca el final de la prosperidad económica y la armonía social venezolana (Coronil y Skurski, 1991. Cit. Ferrándiz, 1996). Y no es que antes de esa fecha la violencia ciudadana e institucional no fueran usuales, lo sorprendente fue su progresiva escalada.

A principios de la década de los 90 se oía hablar de las «zonas rojas», lugares peligrosos de exclusión situados en los barrios marginales, que había que evitar. Los medios de comunicación, aunque politizados y sensacionalistas, ofrecían por esas fechas cifras alarmantes de 20 o 30 muertos durante los fines de semana en Caracas, atribuidos en su mayoría a los llamados «malandros», jóvenes de los barrios estigmatizados como delincuentes. No obstante, como bien señala Ferrándiz (1996), los sectores marginales causantes de este tipo de violencia son a su vez víctimas de la violencia estructural que genera el sistema político, económico y social.

La violencia sangrienta y mortífera asentada en los barrios, con el paso del tiempo cada vez era más habitual presenciarla o sentirla en el interior de Caracas, "ciudad peligrosa», como se consideraba desde cualquier punto del país hacia 1990. De manera progresiva otras ciudades como Maracaibo o Valencia comenzaron a tener la misma consideración. Ya a finales de la última década del siglo XX cualquier ámbito citadino era potencialmente violento, los asaltos, 
secuestros, muertes por robo o ajustes de cuentas, eran cada vez más comunes. Y en la primera década del nuevo siglo el estado de inseguridad alcanza las áreas rurales extendiéndose por la totalidad del país.

«La delincuencia en Venezuela es un asunto de salud pública» aparece en un editorial del $A B C$ de Valencia en septiembre de 2010 (Sierra, 2010). «Nuestra situación es mucho más grave, comparativamente, que el crimen organizado de México. "Aquí los pobres matan a los pobres"”, señala el investigador y profesor universitario Roberto Briceño.

En 1998 por cada 100 homicidios cometidos en el país se realizaban 111 detenciones; mientras que en 2007, 2008 y 2009 por cada 100 se realizaron 9 ( $A B C$, Valencia, 2-9-2010); colocándose así la falta de protección policial ciudadana como una de las principales razones de su incremento.

En 1988 se cometieron 1.500 homicidios, en 1989 con el «Caracazo» subió de manera considerable. En el 90 y 91 no aumentaron. En 1992, con los dos intentos de golpe de Estado y posterior crisis institucional, subió a 3.300. En 1994 hubo 4.730 y durante los cinco años de gobierno de Caldera se mantuvo estable, pese a atravesar una acentuada crisis económica, con una inflación del $100 \%$ y el barril de petróleo con un precio inferior a 10 \$. En 1999, con Chávez ya como Presidente, subió a 6.000 homicidios; en el 2000 fueron casi 10.000; en 2003 alcanzaron los 11.000, y de manera progresiva subió año tras año hasta los 19.336 de $2011^{2}$ (Sierra, 2010).

Según el Observatorio Metropolitano de Seguridad Ciudadana de Caracas, uno de cada cinco homicidios en el país se produjo en el área metropolitana de la capital. La tasa de Caracas registra unos 210 asesinatos por cada 100.000 habitantes $^{3}$, rebasando a Ciudad Juárez en México (Washington, 2012). El 93\% de las víctimas registradas en 2011 en el área metropolitana de Caracas eran varones de entre 15 y 24 años y la inmensa mayoría murió a consecuencia de los disparos de un arma de fuego, con el robo como principal móvil (23\%) seguido del ajuste de cuentas (Pelegrí, 2012).

2 Mientras que en Colombia los homicidios se redujeron a la mitad entre 2001 y 2011 (de 27.840 a 13.520, en Venezuela se duplicaron (Socorro, 2012).

3 Como cifras de contraste: la tasa de USA es de 6 homicidios por cada 100.000 habitantes; la de Canadá de 1.4; la de Francia de 1; y la de Japón e Inglaterra aún menos (Socorro, 2012). 
Por otro lado, el «Estudio global sobre el homicidio», publicado en octubre de 2012 por la ONU, situó a Venezuela como país sudamericano con el índice más alto y el $4 .^{\circ}$ de América por detrás de Honduras, El Salvador y Jamaica. En cuanto a los secuestros, cifras extraoficiales atribuidas a la policía científica dan cuenta de que en 2011 se denunciaron 1.150 casos en el país, lo que a juicio del criminólogo Fermín Mármol sitúa a Venezuela como el 8. ${ }^{\circ}$ país con más secuestros del mundo (Pelegrí, 2012).

Con todo ello, la desigualdad se redujo en Venezuela de manera significativa. Según el coeficiente de Gini —una escala de 0 a 1 usada para medir las dispersiones de ingreso y riqueza—, la desigualdad en el país se redujo de 0.498 en 1998 a 0.412 en 2008. Y los Índices de Desarrollo Humano de las Naciones Unidas registró un incremento de 1\% anual en la última década (Washington, 2012). ¿Por qué entonces ante esas cifras aumenta la inseguridad?

Según algunos, todo se debe a la falta de control policial (Sierra, 2010). Según otros al proceso de desafección política, de pérdida de confianza en las instituciones, en el sistema democrático (Aguilar, 2010: 156). A lo que se añade: la situación de impunidad, el elogio que de la violencia hacen los líderes, o la ruptura con las normas que regulan el pacto social (OVV, 2012).

De otro modo, desde la óptica de los seguidores del Presidente Chávez, la violencia que vive el país es:

[...] consecuencia de una herencia transmitida por los viejos gobiernos y que, aún en tiempos de revolución estamos cobrando, pero que no va más allá de los lamentables ejemplos de países hermanos que no solo viven en la violencia, sino que además parecieran estar lejos de toda esperanza. (Urdaneta, 2012).

En esa línea entienden que quien mata a otro por un Blackberry vive frustrado por los valores burgueses y quien le puso el arma fue el sistema opresor que promueve la opulencia de unos a cambio de la miseria de otros.

\section{Casos heterogéneos}

Han pasado ya 22 ańos desde que en 1990 llegara por primera vez a Venezuela y, desde entonces son numerosas las visitas realizadas a ese país, algunas de ellas 
por tiempo prolongado de hasta seis meses, y siempre por motivos académicos (investigador o docente) como profesor universitario.

Copellanos y Adecos se disputaban el poder y se alternaban en aquellos tiempos en el gobierno de la nación, hasta que en 1998 llegó Chávez; y qué duda cabe que con él, Venezuela se ha visibilizado más internacionalmente, no voy a entrar en por qué, ni tampoco hablar del singular Presidente que ha ocupado de manera casi monográfica las conversaciones de los venezolanos en lo que llevamos de siglo.

De entre las muchas circunstancias que han cambiado en ese país, como ya mencionaba, la inseguridad ciudadana y la violencia social ocupa una de las páginas más notables: los secuestros exprés, asaltos, asesinatos por robo o por ajustes de cuentas, ya no solo son característicos de Caracas sino que, de manera generalizada, se han extendido por el ámbito urbano y rural de todos los Estados. La delincuencia se ha propagado de forma alarmante y nadie puede considerarse a salvo en ninguna parte. Pero más allá de los delincuentes queremos llamar la atención en las conocidas como "gentes de bien», en los ciudadanos y ciudadanas corrientes, y en las actitudes que muestran hacia la integridad física de los otros o de uno mismo, cuando ésta se encuentra de alguna manera amenazada en los tiempos que corren. Sin pretender aquí generalizar las actitudes de los venezolanos, si queremos mostrar una serie de hechos que han dejado de ser aislados y marcan una clara tendencia social. Describiré tan solo cuatro casos concretos, fruto de la experiencia vivida, que por los significados que encierran ayudaran a entender el problema.

Primer caso: Paseaba una mañana, en febrero de 2005, por la Plaza Bolívar de Caracas y un grupo de unas 10 personas observaba cómo dos policías indican a un hombre con sangre en una pierna que se siente en un banco y salga fuera de la zona ajardinada, mientras los observadores se preguntaban entre sí ¿qué es lo que le había ocurrido? Continué mi paseo y pasados unos 45 minutos, de vuelta por el mismo lugar, el herido no se había movido del sitio y un numeroso grupo de más de 50 personas, divididos en dos bandos, no paraban de lanzarse mutuamente insultos, mientras que los policías, que también habían crecido en número, se ocupaban de que no llegaran a las manos. El tema de discusión era en efecto el herido, pero lejos de interesarse por su estado de salud, un sector (el antichavista o «escuálido») acusaba la inoperancia del gobierno por no evacuarlo como es debido; mientras el otro sector (el chavista) lo acusaba de estar simulando la herida para generar inestabilidad o malestar social. 
La polarización política y social que ha experimentado Venezuela desde 1998 ha generado un clima de radicalismo y fanatismo en donde todo tema de conversación o comportamiento observado se halla bajo sospecha; interpretado por unos como motivo de conspiración hacia el poder establecido, y por otros como mera propaganda del mismo; de ese modo, como pudimos apreciar, incluso caer enfermo o herido puede ser sospechoso y juzgarse en clave política.

Segundo caso: Era por la tarde, un día de enero de 2007, cuando, de camino a un centro de llamadas telefónicas, en las proximidades de la Catedral de Puerto Ayacucho, los gritos de varias personas me alertan de dos jóvenes que corren desesperados hacia el lugar donde me encuentro, perseguidos por varios agentes de la Guardia Nacional armados; al parecer habían intentado robar. A escasos cuatro o cinco metros de mi posición ambos son detenidos; uno de ellos es reducido y golpeado en el suelo, con las esposas puestas; mientras el otro seguía en pie con los brazos en alto, sin hacer caso a la orden de «tírate al suelo» que le profería el corpulento agente que tenía en frente; sin mediar más palabras, dicho agente le disparó por dos veces al costado y viendo que no caía le apuntó directamente al corazón, con el cañón a escasos 15 centímetros de su cuerpo, haciendo esta vez que se desplomara fulminado por el disparo. Al comprobar que había muerto, los seis o siete guardias nacionales allí presentes transmitían a los ciudadanos que había sido en defensa propia, circunstancia totalmente falsa como vimos. El segundo espejismo de este caso lo pudimos contemplar cuando buena parte de la multitud que se iba concentrando en el lugar, con el cadáver aún en el suelo, no paraba de hacer chistes, bromear y ridiculizar la situación, como si de un juego se tratara.

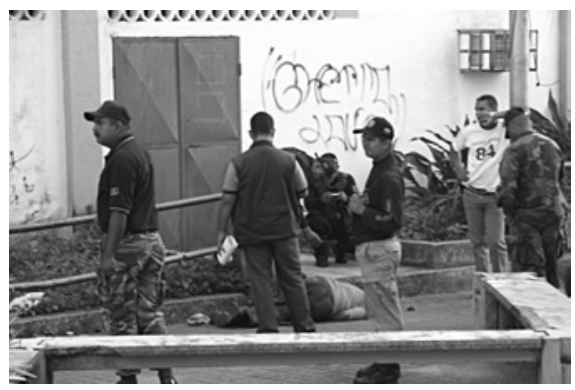

Agentes de la Guardia Nacional rodean el cadáver abatido a tiros por uno de ellos. Puerto Ayacucho, enero de 2007.

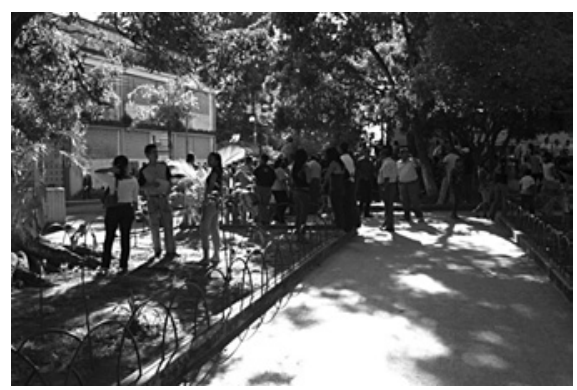

Gentío concentrado en Pza. Bolívar se mantiene expectante próximo al cadáver. Puerto Ayacucho, enero de 2007. 
En Puerto Ayacucho había crecido mucho el nivel de homicidios en los últimos años, nos decían; la población se había acostumbrado a escuchar ese tipo de noticias; pero qué pensar cuando una multitud contempla con ironía un cadáver humano recién asesinado y bromea sobre el hecho. Del comportamiento del agente de la autoridad, en este caso concreto un asesino con sueldo del Estado, sobran las palabras.

Tercer caso: A principios de junio de 2009, con ocasión de una fiesta privada de cumpleaños en la ciudad de Mérida, avanzada ya la noche, en una de las tertulias que se produjeron, donde fundamentalmente se conversaba de temas sociales y políticos, uno de los jóvenes con formación universitaria, como todos los presentes, y que parecía estar bien informado de lo que ocurría en su país, opinó sobre los numerosos asesinatos que venían ocurriendo en San Cristóbal (ciudad fronteriza con Colombia) por obra de grupos de sicarios organizados, diciendo que le parecía bien que exterminaran o limpiaran la ciudad y el país de indeseables, teniendo en cuenta además que dentro de ese grupo no solo estaban bajo el punto de mira los delincuentes comunes y narcotraficantes, sino también los mendigos, las prostitutas y los homosexuales. Su opinión quedó sin réplica ¿les parecería sensata a todos?

La reunión de jóvenes tertulianos no despertaba aparentemente ninguna sospecha, se trataba de una entre muchas en las que el ambiente distendido de fiesta hace que se estrechen las distancias y cada cual exprese sus pensamientos o sus emociones libremente, pero qué pensar de un joven universitario, relativamente ilustrado, que aprueba el exterminio, la limpieza de los indeseables sociales y nadie de los presentes le replique.

Cuarto caso: El 8 de enero de 2006, con un retraso de dos horas aterricé en el aeropuerto de Maiquetía a las 18:30 portando un escueto equipaje. Meses antes se había derrumbado el viaducto que conduce a Caracas y el caos circulatorio era enorme. Tras cambiar $100 €$ a un joven librecambista, convine con un taxista pirata el precio por el que me llevaría al hotel por el camino más rápido. «¿Está bien el aire señor? [...] ¿De dónde viene señor? [...] ¿Viene para mucho tiempo? [...] ¿Turismo o trabajo? [...] ¿Disculpe, profesor de qué es usted?» Demasiadas preguntas en tan poco tiempo, lo que unido al aspecto hermético del coche con los cristales ahumados que impedían desde fuera ver lo que había en su interior, me causó un mal presentimiento. Un coche parado en el arcén de una carretera casi solitaria, con el capó levantado y cinco hombres a su alrededor, confirmó la sospecha: "A ver qué problema tienen estos panas (amigos)». Inmediatamente 
probé abrir la puerta y comprobé que tenía el seguro echado. De repente abordaron nuestro vehículo, uno se sentó junto al conductor y otro junto a mí. «Somos la guerrilla, colabore y no le pasará nada, si no colabora le meto un tiro y está muerto». Estas palabras fueron las primeras que pronunció el cabecilla sentado al lado del conductor y vuelto hacia mí, mostrándome en la mano izquierda una placa identificativa que vi fugazmente y una pistola en la derecha que en ese momento me apuntaba al pecho.

Me pidieron el pasaporte y hecha la presentación fueron directo al grano: «Deme la cartera, [...] deme todo el dinero, [...] le dije todo el dinero, vamos démelo. [...] No me mienta, colabore y no le pasará nada». Para no alargar la historia, tras varios registros con el coche en marcha me sacaron todo el dinero que llevaba en efectivo y los objetos de valor, después de dos horas de intimidaciones y amenazas pistola en mano, con frases como: «Te vamos a dar un tiro y dejar por aquí»; «No has colaborado, has mentido todo el rato y te vas a morir»; «Esta es la última oportunidad que te doy, la última, dame el resto o aquí te mueres»; «Sigues diciendo mentira, [...] Ya no te creemos. Dime ya el número pin (de la tarjeta de crédito) o te disparo».

Convencidos de no poder sacarme más, me dejaron en la puerta de un motel en Catia La Mar con el dinero justo para pasar la noche. Momentos antes, el cabecilla me indicó: «No somos hampa, somos la guerrilla [...] Si hubieras caído en manos del hampa te hubieran dado un tiro y te habrían soltado por ahí, se llevarían todo».

Afortunadamente el secuestrado en este caso, con el miedo que se le puede suponer, mantuvo la serenidad en todo momento y no fue presa del pánico, aunque no hizo caso a la última amenaza de los secuestradores: «Tu conoces como son las cárceles aquí, si denuncias esto o hablas con alguien la vas a conocer y no volverás a tu casa más nunca, te vamos a tener controlado todo el tiempo y sabemos lo que haces».

Los atracos con secuestro están a la orden del día, mucha gente vive temerosa de ser algún día víctima de ello, y salir con vida del trance más que de la colaboración del secuestrado, depende de con quién te toque, ya que, como se sabe, «el hampa» dispara antes de registrar.

Aunque se trate de cuatro casos anecdóticos, no son hechos aislados, muestran actitudes que ponen de manifiesto, entre otras consideraciones, la falta de 
confianza en las fuerzas del orden y en el sistema judicial, así como una renovada sensibilidad hacia la inseguridad y criminalidad cotidiana, que los ciudadanos comunes, la «gente de bien», encaja con resignación y una buena dosis de frialdad.

\section{Claves para la comprensión del fenómeno}

Como señala el Observatorio Venezolano de Violencia (2012): «la aparición de elevados y sorprendentes incrementos de violencia criminal coincide con situaciones cercanas a las guerras». Ocurrió en Gran Bretaña o Alemania tras la Primera y Segunda Guerra Mundial; en USA acabada la Guerra Civil; en El Salvador concluidos los Acuerdos de Paz; o en Colombia con la guerra entre el Gobierno con la guerrilla y los paramilitares. En Venezuela, sin embargo, la violencia ha crecido sobremanera sin haber estado involucrada en guerra alguna, ¿por qué así?

El número de casos violentos con resultado de muerte es enorme (19.336 en 2011, recordamos), y si tipificáramos toda la casuística existente, con toda probabilidad habría casos representativos de cada una de las tipologías elaboradas por los distintos autores: violencia primitiva, reaccionaria, moderna (Tilly, 1978); hostil, instrumental (Alderman, 1974); política, cultural, estructural, simbólica, cotidiana, de género (Clastres, 1980; Galtung, 1981; Bourdieu, 2000; Scheper-Hughes, 1997, Fisas, 1998); etc. E igualmente, analizando caso a caso, en cada uno de ellos destacaría alguno de los factores citados en la literatura: el instinto de supervivencia (Lorenz, 1974), el aprendizaje social por imitación a través de los medios de comunicación (Bandura, 1973), la frustración crónica (Dollard, 1936), el ambiente masivo (Blanchard y Chesca, 1986), el estilo subcultural (Clarke, 1978; Marsh, 1978), las desiguales relaciones de clase (Tylor, 1982).

Los cuatro casos descritos en el apartado anterior constituyen una muestra significativa basada en la propia experiencia que ilustra lo que ocurre a diario y a lo que se está expuesto: situaciones o conversaciones cotidianas que se vuelven de pronto conflictivas como fruto de la polarización y el fanatismo político; abusos y delitos policiales amparados en la impunidad; noticias de asesinatos a manos de sicarios que a parte de la población le parecen justificados; o robos por secuestro con intimidación. 
Borda $(1985,35)$ aplicó el término «conflicto total» o «conflicto de destrucción» a la violencia generalizada que se daba en Colombia por los años 50, la cual jugó un papel consuetudinario en su historia. Sin establecer parangón con el país vecino, ya que el enfoque de este ensayo no es holístico ni comparativo sino subjetivista y contextual, nos quedamos con el término para ilustrar la idea de que en cualquier escenario, momento, circunstancia o por cualquier motivo, se puede desencadenar una acción violenta, de lo cual la gente es consciente y cada vez está más acostumbrada a ello, como ocurre en la Venezuela actual.

La permanente incertidumbre instalada en la cotidianeidad, donde cualquier situación se puede tornar peligrosa y el azar puede hacer que hasta el más inocente acto de dar un paseo por la calle o acercarse a un negocio a comprar unas arepas puede convertirse en una acción arriesgada, genera en las personas una sensación de ansiedad ante el estado de indefensión y falta de control sobre el entorno y sus propias vidas. A la vista de la inseguridad y violencia que asiste al país, difundida por los medios de comunicación, con frecuencia de manera distorsionada, y vivida de manera directa en propia experiencia o de manera indirecta por lo que cuenta el vecino, amigo o conocido que le ha ocurrido, provoca en las personas perturbaciones de amplio espectro que afectan a la conducta, la cognición y el estado emocional. La incertidumbre sobre la propia integridad cada cual la experimenta a su modo, unos verbalizando y sacando fuera sus frustraciones de manera constante en cualquier momento y lugar, otros guardándolas dentro para compartirlas solo con los más allegados, procurando no destacar o señalarse en nada por la desconfianza que genera el otro. Cada cual personaliza y vive en efecto la indefensión ante el caos a su manera, aunque dos conductas bien distintas sobresalen en la ciudadanía: la mostrada por lo general en la vida cotidiana individual marcada por el temor, la resignación, y la esperanza de no toparse con el hampa; y la expresada en las concentraciones o manifestaciones públicas, organizadas o espontáneas, donde la unión ciudadana, el hecho de encontrarse y sentirse juntos ante la adversidad dan muestras de resistencia, de enfado y de solidaridad con las víctimas de los infortunios de la que muchas veces ellos mismos se sienten protagonistas.

Sin duda son muchos y variados los factores a considerar para entender el conjunto de situaciones, pero nos resulta especialmente sugerente la visión que ofrece el Observatorio Venezolano de Violencia en su último informe de 2011 (Briseño, Ávila y Camardiel, 2012), en cuanto que, a diferencia de las tesis que han dominado las interpretaciones de la violencia en Venezuela y América Latina en ańos pasados, ya no es la pobreza, el desempleo, la desigualdad o el capitalis- 
mo los principales causantes de la misma, sino la falencia institucional, la impunidad, el alarde que hacen los líderes de ella, o la ruptura con las normas sociales. El colapso de las instituciones que aplican la ley y la mayor implicación del país en el narcotráfico, son igualmente citadas en algunos medios (Washington, 2012). La acción política, con todas sus implicaciones, se coloca por tanto en el punto de mira como principal responsable de la generalización de la violencia.

De una población despolitizada que en 1990 apenas protestaba por los numerosos atropellos e injusticias de que era víctima, que contemplaba con la resignación de unos y la indignación e impotencia de otros el expolio de las grandes riquezas que posee, por parte de banqueros, grandes empresarios y políticos corruptos de cualquier signo (COPEI o $\mathrm{AD})^{4}$; de ese panorama se ha pasado a otro bien distinto en donde la población está totalmente politizada, dominada por la política, al extremo de llevar cualquier conversación, ya sea de cine, deporte, alimentación, naturaleza o sexo, a ese terreno, véase si no el primer caso referido en el apartado anterior. Todo tiene ahora una lectura política, nada ocurre al azar o de manera inocente, cualquier acontecimiento o comentario que se haga está bajo sospecha: ¿qué pretenderá?. El importante valor de que la gente cobre conciencia política, que se preocupe por ser tenida en cuenta, sabedora de que son agente de cambio, queda desvirtuado por la influencia que sobre ella provoca la dialéctica empleada por el Gobierno: la del amigo - enemigo; dialéctica que tiene como resultado la polarización política y división social; dialéctica que ha calado hondo y llegado hasta los sectores más tradicionales, hasta los pueblos y comunidades indígenas que en muchos casos han entrado en la dinámica de ser o estar con los chavistas o con los antichavistas, propiciando incluso separaciones y enemistades familiares y comunitarias ${ }^{5}$.

Unida a esa dialéctica de conmigo o contra mí, que empleada desde el Gobierno de la Nación ya es de por sí una actitud en cierto modo violenta por dañar a un sector de la población, no ser ecuánime, situándose el poder en una posición nada conciliadora o unificadora con respecto a los ciudadanos; el problema se agrava cuando la máxima autoridad del Estado emplea consignas como: «el pueblo en armas», «hasta la victoria siempre» o «vencer o morir».

${ }^{4}$ COPEI es acrónimo de Comité de Organización Política Electoral Independiente; y AD lo es de Acción Democrática.

${ }^{5}$ La comunidad Yukpa de Toromo, por ejemplo, situada en la sierra de Perijá, con apenas 150 miembros se separó físicamente en dos, abandonando la mitad de sus integrantes el poblado y construyendo uno nuevo poco más arriba, todo ello por problemas de adhesión política. 
Si aceptamos la idea de que la visión del mundo se encuentra condicionada o influida por el lenguaje, suavizando la proposición más radical de Whorf al decir que la lengua determina la cognición (Whorf, 1940; cit. Velasco, 2009 [2003]: 280), la dialéctica empleada por las máximas autoridades del país, de la que se hacen eco quienes están por debajo en el escalafón, hace entendible buena parte de las emociones, pensamientos y maneras de obrar cargadas de miedo y resentimiento, cada vez más interiorizadas por todos.

Sin duda que para entender un hecho concreto de violencia, en cualquiera de los cuatro casos referidos, es preciso caracterizar y examinar detenidamente todo el proceso en el cual se gesta y contemplar con detalle su especificidad; sin olvidar el marco social conflictual que lo envuelve o en donde se inscribe, el conflicto social en su conjunto. En tal sentido, es necesario realizar trabajos sistemáticos que desvelen la complejidad que encierra cualquier comportamiento violento, como propio que es de un ser complejo como el humano. Sin embargo, por la evolución de los acontecimientos en el caso venezolano, sería oportuno considerar como telón de fondo el estilo propio de hacer política, con sus gestos y su lenguaje; así como la anomia y polarización generada en la población, desamparada ante la forma de actuar de las fuerzas y servicios de seguridad del Estado y dividida ante la actitud de sus líderes; población desconfiada que observa la impunidad que asiste a quienes obran fuera de la ley, y de la que el tiempo dirá si seguirá resignada a vivir bajo el principio de «sálvese quien pueda» o acabará por estallar.

\section{Conclusión}

La «Revolución» que se predica sin descanso bajo la idea de «solidaridad», sin duda ha modificado la estructura económica, social y política de Venezuela, pero además está afectando seriamente a las conciencias, al núcleo duro de la cultura, el que más cuesta cambiar y recuperar, aunque, por los hechos observados aquí a modo de muestra, parece que ante el derecho a la vida no es precisamente solidaridad lo que se manifiesta. En cualquier caso, lejos de reprochar nada a la sufrida población venezolana, estas palabras no tratan más que hacer reflexionar sobre la condición humana, la cual, ante situaciones límites suele manifestar sus instintos más básicos, en este caso de supervivencia, para hacer frente a las consecuencias que trae consigo el proyecto personal de un iluminado más de la historia. 


\section{Bibliografía}

Aguilar, V. (2010). «Desafección política y crisis institucional en Venezuela», Revista Venezolana de Gestión Pública, 1: 139-160.

Alderman, R. B. (1974). Psychological Behavior in Sport, Philadelphia: W. B. Saunders.

Bandura, A. (1973). Aggression: A Social Learning Analysis, Englewood Cliffs, N. J: Prentice-Hall.

Baselga, E. y Urquijo, S. (1974). Sociología y violencia, Bilbao: Mensajeros.

Blanchard, K. y Chesca, A. (1986). Antropología del deporte, Barcelona: Bellaterra.

Borda, F. (1985). «Lo sacro y lo violento, aspectos problemáticos del desarrollo en Colombia», en A. DíAz (comp.), Once Ensayos sobre la Violencia en Colombia, Bogotá: Fondo Editorial CEREC y Centro Gaitán, pp. 79-88.

Bourdieu, P. (2000). La dominación masculina, Barcelona: Anagrama.

Bourgois, P. (2001). "The continuum of violence in war and peace: post-cold war lessons from El Salvador». Ethnography, 2 (1): 5-34.

Briseño, R.; Ávila, O. y Camardiel, A. (2012). Violencia e Institucionalidad, Caracas: Alfa.

Cagigal, J. M. (1976). Deporte y agresión, Barcelona: Planeta.

Clarke, J. (1978). «Football and Working Class Fans: Tradition and Change», en R. Ingahm (ed.), Football Hooliganism: The Wider Context, London: Inter-Action Imprint.

Clastres, P. (1980). «Arqueología de la violencia: la guerra en las sociedades primitivas», en Investigaciones en Antropología Política, Barcelona: Gedisa, pp. 181-216.

Coronil, F., y Skurski, J (1991). «Dismembering and Remembering the Nation: The Semantics of Political Violence in Venezuela», Comparative Studies in Society and History, 33: 288-337.

Coser, L. (1967). Continuities in the Study of Social Conflict, New York: Free Press.

Dollard, J. et al. (1939). Frustration and Aggression, New Haven: Yale University Press.

Durkheim, E. (1967). De la División del Trabajo Social, Buenos Aires: Ed. Shapire.

Feixa, C. y Ferrándiz, F. (2001). «Violencias y culturas: introducción», en Simposio 7. Violencias y Culturas. IX Congrés d'Antropologia FAAEE. Barcelona.

Ferrándiz, F. (1996). «Malandros, africanos y vikingos: violencia cotidiana y espiritismo en la urbe venezolana». Simposio VI. VII Congreso de Antropología Social. Zaragoza, pp. 125-137. 
Ferrándiz, F. y FeIXA, C. (2004). «Una mirada antropológica sobre las violencias», Alteridades, 14 (27): 159-174.

FISAs, V. (ed.) (1998). El sexo de la violencia. Género y cultura de la violencia, Barcelona: Icaria.

Galtung, J. (1981). «Contribución específica de la irenología al estudio de la violencia y su tipología», en VV. AA., La violencia y sus causas, Paris: UNESCO, pp. 91-106.

- (1990). "Cultural violence», Journal of Peace Research, 3 (27): 291-315.

García Ferrando, M. (1990). Aspectos sociales del deporte. Una reflexión sociológica, Madrid: Alianza Deporte.

Garriga, J. y Noel, G. (2010). «Notas para una definición antropológica de la violencia: un debate en curso» Publicar, Año 8, n. ${ }^{\circ}$ 1, pp. 97-121.

GIRARD, R. (1983). La violencia y lo sagrado, Barcelona: Anagrama.

Guzmán, A. (1990). «Sociología y violencia», en Documento de Trabajo n. ${ }^{\circ} 07$. Cali: CIDSE, Universidad del Valle, pp. 1-51.

Instituto Nacional de Estadística (2012). Censo Nacional de Población y Vivienda 2011, Caracas: I. N. E.

Lorenz, K. (1974). Consideraciones sobre la conducta animal y humana, Barcelona: Plaza y Janes.

Marsh, P. (1978). Agro: The Illusion of Violence, London: Dent.

Martin, G. (2000). "The 'tradition of violence' in Colombia: Material and Simbolic Aspects», en G. Aujmer y J. Aвbniк (ed.), Meanings of Violence. A Cross cultural perspective, New York: Berg.

Marx, K. (1971). El Capital, México: Fondo de Cultura Económica.

Observatorio Venezolano de la violencia (OVV) http:/www.observatoriodeviolencia.org.ve/site/

Pelegrí, A. (2012). «El 2011 fue el año más violento en calles y prisiones de Venezuela», Publicación eltiempo.com. Sección Internacional. AFP. 12-3-2012. http://www.google.com/hostednews/afp/article/ALeqM5gbtDx6vm zZ1VoKCui_1v9TjxI5Q?docId=CNG.ce21 ca538f23556ea5a80e4128de49b2.521

Scheper-Hughes, N. (1997). La muerte sin llanto: Violencia y vida cotidiana en Brasil, Barcelona: Ariel.

Sierra, M. F. (2010). "La violencia en Venezuela es un asunto de salud pública», ABC de la semana, 2-9-2010. Valencia. http://www.abcdelasemana. com/2010/09/04/\%E2\%80\%9C-la-delincuencia-en-venezuela-es-un-asunto-desalud-publica $\% \mathrm{E} 2 \% 80 \% 9 \mathrm{D} /$ 
Socorro, M. (2012). "Contra mitos, propagandas y risitas», El Nacional, 24-6-2012. http://venezuelaysuhistoria.blogspot.com.es/2012/06/la-amiga-y-periodista-milagros-socorro.html

Taylor, I. (1982). «Class, Violence and Sport», en H. Cantelon y R. Gruneau (ed.), Sport, Culture and The Modern State. Toronto: University of Toronto Press.

Tilly, C. (1978). From Movilization to Revolution, Reading, Mass: Addison.

URdaneta, W. (2012). "La Violencia en Venezuela». www.aporrea.org 9-10-2012. http://www.aporrea.org/tiburon/a152569.html

Velasco, Honorio (2009 [2003]). Hablar y pensar, tareas culturales. Temas de Antropologia Cognitiva y Antropología Lingüistica, Madrid: UNED.

Velho, G. y Alvito, M. (1996). Ciudadanía e violencia, Río de Janeiro: UFRJ/FGV.

Washington (2012). "Delincuencia, 'el cáncer' que padece Venezuela». Publicación eltiempo.com. Sección Internacional. AFP. 5-3-2012. http://www.eltiempo.com/mundo/latinoamerica/ARTICULO-WEB-NEW_NOTA_INTERIOR-11276386.html

Weber, M. (1969). Economía y Sociedad, México: Fondo de Cultura Económica.

Recibido: 11/06/2013

Aceptado: 15/09/2013 